\title{
Can we use the peritoneum of deceased donors as the vascular substitute for reconstructing the middle hepatic vein in living donor liver transplantation?
}

\author{
Seok-Hwan Kim
}

Division of Transplantation, Department of Surgery, Chungnam National University Hospital, Cheongju, Korea

Background: The interest in vascular substitutes has recently increased. We evaluated the feasibility of using a homologous parietal peritoneum (HPP) as a vascular substitute for venous reconstruction during abdominal surgery.

Methods: The inferior vena cava was replaced with an HPP after cross-linking with glutaraldehyde in 15 rabbits. At 7, 14 , and 28 days, the patency rate, outer and inner graft diameters, histology, and immunohistochemistry were evaluated.

Results: Both the 7- and 14-day groups maintained vascular patency. Vascular patency was maintained in three rabbits in the 28 -day group. The inner diameters of the anastomotic sites were $6.12 \pm 0.20 \mathrm{~mm}, 5.63 \pm 0.14 \mathrm{~mm}$, and $2.22 \pm 0.23 \mathrm{~mm}$ in the 7 -, 14-, and 28-day groups, respectively. The mid-point inner diameters of the HPP grafts were $6.21 \pm 0.13 \mathrm{~mm}, 5.82 \pm 0.16 \mathrm{~mm}$, and $2.12 \pm 0.24 \mathrm{~mm}$ in each group, respectively. Endothelial cell proliferation on the HPP graft surfaces in all groups was based on the histological findings from the first group. Multiple neo-vascularizations of the HPP graft were found in the 14- and 28-day groups, indicating neo-media formation. Acute inflammation appeared to progress to the entire layer of the HPP graft without an intraluminal thrombus, but the graft was patent in the 14-day group. In the 28-day group, two rabbits showed near-total occlusion and a thrombus formed in the HPP graft at the anastomosis site with severe stricture; however, the rabbits were alive and had collateral vessel formation.

Conclusions: Use of the HPP is feasible for venous reconstruction in abdominal surgery.

Corresponding author: Seok-Hwan Kim

E-mail:kjxh7@naver.com

\footnotetext{
(C) The Korean Society for Transplantation

This is an Open Access article distributed under the terms of the Creative Commons Attribution Non-Commercial License (http://creativecommons.org/licenses/by-nc/4.0/) which permits unrestricted non-commercial use, distribution, and reproduction in any medium, provided the original work is properly cited.
} 